\title{
Information access rights in FOIA and FOISA - fit for purpose?
}

\author{
Karen Mc Gullagh*
}

\section{A. Introduction}

The Freedom of Information Act 2000 (FOIA) enacted by the Westminster Parliament applies to public authorities in England, Wales and Northern Ireland and to UK public authorities that operate in Scotland e.g. the BBC, whilst the Freedom of Information (Scotland) Act 2002 (FOISA), promulgated by the Scottish Parliament, applies to Scottish public authorities. ${ }^{1}$ Both Acts commenced on $1^{\text {st }}$ January 2005, and have been hailed as success stories - helping the public and the press to obtain information on issues such as: problems with a nuclear reactor, ${ }^{2}$ inadequate health services, ${ }^{3}$ school closures, ${ }^{4}$ a lack of suitable quality housing for people with disabilities ${ }^{5}$ and so forth. ${ }^{6}$ Nevertheless, FOIA has been described as 'a brilliant piece of trompe l'oeil, a sheep in wolf's clothing, ${ }^{7}$ appearing to offer a legally enforceable right of access to governmental information subject only to specified and justifiable exemptions when, in fact, it offers weak information access rights. By contrast, it has been asserted that 'Scotland has most robust Freedom of Information regime in the UK.' ${ }^{8}$ A two-strand approach is used to test the veracity of these claims and determine whether both jurisdictions have freedom of information laws that are fit for purpose as the Acts enter their second decade. Firstly, an assessment of the degree of compliance of both Acts with principles that have been endorsed by the United Nations as forming the normative foundations of freedom of information laws is undertaken. Secondly, the Acts are compared to ascertain whether FOISA does in fact offer stronger information access rights than FOIA, and if so, what lessons the UK could draw upon to strengthen FOIA. The analysis will demonstrate that the Acts are creatures of their respective Parliaments and that distinct 'political cultures' have influenced their evolution over the past ten years leading to significant divergences between the two. It concludes that, at present, FOISA offers stronger information access rights whereas FOIA offers weaker rights, but both Acts should be amended to

\footnotetext{
* Lecturer in Law, University of East Anglia. I am grateful to Prof Morten Hviid, Prof Mark James, Dr

${ }^{1}$ As a result of the Brexit referendum, the UK may cease to be a member of the European Union.

Whilst this may impact upon information requests made under the Environmental Information

Regulations 2004, it will not affect requests for information made under FOIA or FOISA since these are domestic Acts of Parliament.

2 'The end of FoI? 9 things we only know because of the Freedom of Information Act,' The Independent (17 July 2015).

3 'Kids as young as 9 sent away for treatment,' The Derry Journal, (16 October 2015).

${ }^{4}$ National Association of Small Schools, 'Scottish Rural Schools Network,' (Newsletter, March 2014).

${ }^{5}$ Inclusion Scotland, Homes for Life? - FOI research into accessible homes for disabled people in Scotland, (2008).

${ }^{6}$ Numerous other examples of FOI requests by the press were provided in the submission to the Independent Commission on Freedom of Information; Johnston Press (2015) 'A response to the Call for Evidence by the Independent Commission on Freedom of Information,' available at: https://www.gov.uk/government/uploads/system/uploads/attachment_data/file/483322/Johnston_Press_ Submission.pdf.

${ }^{7}$ R Austin, 'Freedom of Information Act 2000 - a sheep in wolf's clothing?' in J Jowell, \& D Oliver (eds), The Changing Constitution, $6^{\text {th }}$ edn (2007) 397.

${ }^{8}$ The Scottish Government, 'More bodies eligible for FOI requests,' (31 March 2014), available at:

http://news.scotland.gov.uk/News/More-bodies-eligible-for-FOI-requests-aec.aspx
} 
ensure full compliance with the UN endorsed principles if both jurisdictions are to have information rights that are fit for purpose as the Acts enter their second decade.

\section{B. Comparative evaluation - normative principles}

The highly respected NGO, ARTICLE 19, synthesized nine normative principles from international and regional laws (e.g. UNDHR and ECHR) and judicial pronouncements in 1999 and updated them in 2015. ${ }^{9}$ These United Nations endorsed principles collectively constitute best practice standards in respect of right to information legislation. ${ }^{10}$ This article analyses compliance with six of the nine principles only, namely: Maximum disclosure, Obligation to publish, Promotion of open government, Limited scope of exceptions, Processes to facilitate access and Costs. The Acts are not compared against the open meetings, disclosure takes precedence, or protection for whistleblowers principles since other laws, which are not the focus of this paper, govern these. ${ }^{11}$ The evaluation is timely as the first UNESCO commissioned comparative survey of freedom of information laws compliance with these principles was conducted in $2003^{12}$ prior to the implementation of FOIA and FOISA and the second in 2008 shortly after their implementation when insufficient data such as Tribunal decisions, court cases and information commissioner reports existed to properly assess their compliance, ${ }^{13}$ whereas this article provides the first comparative assessment of compliance with the updated principles. Compliance is evaluated by reference to ministerial speeches, white papers, parliamentary debates, post-legislative reviews, public opinion surveys and statistics on performance, Commissioner decisions and cases heard by Tribunals and Courts in both jurisdictions.

(1) Maximum Disclosure Principle

The 'maximum disclosure' principle seeks to establish a culture of information rights in countries where none has previously existed through recommending the granting of legally enforceable rights not limited by residence or purpose, recommending that the legislation contain broad definitions of information and public authorities, and further, the inclusion of criminal and financial sanctions for actions intended to prevent disclosure, to promote compliance with the law. Both Acts comply with this principle in granting access rights to 'all persons and informal and formal organisations, regardless of citizenship or residence,' 14 and in defining information as 'information recorded in any form,' 15 regardless of its form, status, date received and whether or not it was produced by the public authority which holds it at the time the

\footnotetext{
${ }^{9}$ ARTICLE 19, (1999), The Public's Right To Know: Principles on Freedom of Information Legislation, available at: http://www.article19.org/data/files/pdfs/standards/righttoknow.pdf; The principles were updated in 2015. This article evaluates both acts against the revised principles where these differ from the original principles (currently only available in dual language format), available at: https://www.article19.org/resources.php/resource/38117/en/asia:-the-right-to-know-principles ${ }^{10}$ UN HRC, Report of the Special Rapporteur on access to information, criminal libel and defamation, the police and the criminal justice system, and new technologies, UN Doc.E/CN.4/2000/63; It was referred to by the Commission in its 2000 resolution on freedom of expression; UN CHR, 2000/38: Resolution, Right to Freedom of Opinion and Expression, UN Doc.E/CN.4/RES/2000/63.

${ }^{11} \mathrm{P}$ Birkinshaw, Freedom of Information: The Law, the Practice and the Ideal, $4^{\text {th }}$ edn (2010) 116

${ }^{12}$ T Mendel, Freedom of Information: A Comparative Legal Survey, UNESCO (2003).

${ }^{13}$ T Mendel, Freedom of Information: A Comparative Legal Survey: Second edition revised and updated, UNESCO (2008).

${ }^{14}$ FOIA, s 1(1); FOISA, s 1(1).

${ }^{15}$ s 84 subject to section 51(8) and section 75(2); s 73 FOISA.
} 
request is received.

\section{(a) Public authorities}

Both Acts appear, at first glance, to comply with this principle's recommendation to interpret the term 'public authority' broadly since Schedule 1 of both Acts list a large number of public authorities by name that includes all central government departments and legislative bodies and the armed forces. ${ }^{16}$ Schedule 1 of FOIA lists more bodies than its Scottish equivalent, partly a reflection of Scotland having fewer public authorities since the $\mathrm{BBC}^{17}$ and other bodies such as the Forestry Commission and Scottish Consumer Council were, prior to devolution and continue to be, considered UK-wide public authorities under FOIA. Also, information supplied by a UK Minister or UK Government Department and held in confidence by a Scottish authority is not 'held' by a Scottish authority for the purposes of FOISA, rather the request should be made to the relevant Minister or Department of the UK Government under FOIA - a reflection of the ultimate sovereignty of the Westminster Parliament. ${ }^{18}$

A second aspect of this principle anticipates and provides for changes in government service delivery, in recommending designation as 'public' those 'private' bodies which 'carry out public functions (such as maintaining roads or operating rail lines) or hold decision-making authority or expend public money' thereby ensuring continuing information rights as public service provision is outsourced to private contractors. Extending FOI obligations to private providers of public services is a crucial test of how committed a government is to being truly open and transparent since bodies not classified as 'public authorities' are beyond the scope of the Acts and not legally obliged to respond to information requests. The inclusion of designation powers ${ }^{19}$ in both Acts suggests compliance with this principle. However, the Scottish Government was slow to add to the list of designated bodies, not doing so for the first nine years of the Act. On a positive note, FOISA was amended in 2013 to include a new section, s 7A, which provides that Ministers are obliged to report to Parliament on their use of the designation power every two years and give reasons for not using the power if it hasn't done so in the two-year reporting period. ${ }^{20}$ It has been used regularly since then, to extend FOISA to cover recreational, sporting, cultural or social bodies established and financed, wholly or in part, by local authorities, ${ }^{21}$ contractors who run privately-managed prisons, providers of secure accommodation for children, grant-aided schools and independent special schools, and an organisation that exists to facilitate the commercialisation of intellectual property arising from the staff of NHS Scotland (Scottish Health Innovations Ltd). ${ }^{22}$ These designations are evidence of a FOISA-friendly political culture as the Scottish Government cited parity

\footnotetext{
${ }^{16}$ A public authority is a body listed in Schedule 1 or one designed by order under Section 5 , or a publically owned company by virtue of section 6 FOIA / FOISA. Section 5 or section 6 bodies don't appear in Schedule 1.

${ }^{17}$ S7 FOIA; The BBC is a public authority in respect of information 'held for purposes other than that of journalism, art or literature only.'

${ }^{18}$ S3(2)(a)(ii) FOISA.

${ }^{19}$ Section 5 of both Acts delegates legislative authority to the Secretary of State/Scottish Ministers.

${ }^{20}$ SIC, (2013) Freedom of Information (Amendment) (Scotland) Act 2013: Briefing Note, available at: http://www.itspublicknowledge.info/nmsruntime/saveasdialog.aspx? $l I D=6932 \& s I D=377$

${ }^{21}$ The Freedom of Information (Scotland) Act 2002 (Designation of Persons as Scottish Public Authorities) Order 2013, S.I. 2013/278.

${ }^{22}$ The Freedom of Information (Scotland) Act 2002 (Designation of Persons as Scottish Public Authorities) Order 2016, S.I. 2016/139
} 
of legal responsibilities and equity in terms of accessing information irrespective of sources of funding when designating these bodies and asserted that the benefits outweighed the compliance burden that would be imposed on private contractors. ${ }^{23}$

The Westminster Government was also slow to designate - it took five years from implementation for the power to designate bodies to be utilised ${ }^{24}$ and a subsequent proposed amendment to FOIA $^{25}$ to automatically bring all information held by a contractor (including that held by a sub-contractor) about the performance of a contract within the Acts did not receive support from the Coalition Government. Instead, they favoured introducing a revised code of good practice under section 45 of the Act. ${ }^{26}$ The NGO, Campaign for Freedom Of Information (CFOI) is critical of the code because it is voluntary and lacks sanctions: 'Should an authority choose to ignore the new code, all the Commissioner can do is issue a non-binding "practice recommendation." If a contractor refuses to disclose voluntarily, even this option won't be available. ${ }^{27}$ The ICO recommended that the Act be extended to private bodies providing public services under contract by treating information about the performance of the contract as being 'held' on behalf of the contracting public authority where the contract is over $£, 5$ million in value or continuing over 5 years or where the contractor solely derives its revenue from public sector contracts. ${ }^{28}$ This would, if introduced, ensure that FOIA obligations extend to outsourced contracts, thereby preserving information rights that existed when such contracts were performed by public authorities. The Conservative Government led by Mr Cameron favoured a 'small state' model of government in which many services traditionally provided by the public sector were outsourced to private providers, so it's silence ${ }^{29}$ in response to the ICO's recommendation on this issue was telling, as allowing such bodies to comply with transparency measures on a voluntary basis, with no effective sanctions for non-compliance suggested that it was not truly committed to FOIA. It remains to be seen whether the Conservative Government led by Theresa May will adopt a different approach.

\section{(b) Penalties}

FOIA and FOISA both comply with the maximum disclosure principle requirement to contain provisions imposing criminal sanctions and financial penalties on any

\footnotetext{
${ }^{23}$ Scottish Government, Consultation on Further Extension of Coverage of the Freedom of Information (Scotland) Act 2002 to More Organisations: Scottish Government Response (January 2016) PPDAS62889 (01/16) 4

${ }^{24}$ In 2010, The Academies Act 2010 extended FOIA to academy schools. In 2011, the UK designated the Association of Chief Police Officers, UCAS and the Financial Ombudsman Service; It did so through The Freedom of Information (Designation as Public Authorities) Order 2011.

${ }^{25}$ Transparency and Accountability Bill 2014-2015, Bill 28 55/4, available at: http://services.parliament.uk/bills/2014-15/transparencyandaccountability.html

${ }^{26}$ Hansard, HL Deb, 20 October 2014, col. 450

${ }^{27}$ CFOI, MP's debate amendment to bring contractors' information under FOI Act,' (23 ${ }^{\text {rd }}$ October 2015), available at: https://www.cfoi.org.uk/2014/10/mps-debate-amendment-to-bring-contractorsinformation-under-foi-act/

${ }^{28}$ ICO, 'Freedom of Information, Transparency in Outsourcing: a roadmap,' available at https://ico.org.uk/media/for-organisations/documents/1043531/transparency-in-outsourcingroadmap.pdf

${ }^{29}$ Cabinet Office, The Rt Hon Matt Hancock MP, Written Statement to Parliament: Open and Transparent Government (1 March 2016), available at: https://www.gov.uk/government/speeches/openand-transparent-government
} 
public authority that 'obstructs access to or wilfully destroys information,' 30 but differences in the time frames for commencing prosecutions impact on the effectiveness of each Act. In 2013, FOISA was amended ${ }^{31}$ to extend the time frame for commencing prosecutions from 6 months to three years of the offence being committed. ${ }^{32}$ By contrast, the time frame for commencing prosecutions under FOIA remains 'within 6 months of the offence being committed' 33 - this short time frame has precluded prosecutions by the UK Information Commissioner (ICO) as the time taken by public authorities to investigate time bars prosecutions. In an effort to improve the effectiveness of FOIA the Independent Commission recommended that the Westminster government legislate to make the offence at section 77 of the Act triable either way which would have the effect of removing the time limit for those seeking to bring a prosecution, and would also allow for a custodial sentence for particularly serious acts of destruction, ${ }^{34}$ but the then Government's response to the Independent Commission's report ${ }^{35}$ did not indicate an intention to give effect to this recommendation, suggesting a lack of political support for effective FOIA sanctions.

In summary, the amendment of FOISA to include a biannual review of the use of designation powers ensures compliance with the ARTICLE 19 recommendation to widely define 'public authorities,' whereas, the introduction of a code of practice for private contractors represents a both a weakening of rights under FOIA in comparison to rights under FOISA and incomplete compliance with this principle. Also, the longer prosecution commencement time-frame under FOISA means that it is fully compliant with the ARTICLE 19 principle, whereas the impractically short time period under FOIA means that it is not compliant with this principle and will remain so until a Westminster Government gives legislative effect to the Independent Commission's recommendation that s 77 offences become triable either way. Arguably the Westminster Government's silence on both recommendations reflects the prevailing political culture, that is, the Westminster Government is not truly supportive of FOIA, an argument fully explored below in section C.

(2) Obligation to publish principle

The 'obligation to publish' principle recommends that public authorities proactively publish key information as well as responding to information requests, to promote a culture of openness and transparency that should improve over time. ${ }^{36}$ In compliance

\footnotetext{
${ }^{30}$ s 77 FOIA; s1(b) and s65 FOISA. The maximum fine under FOISA is $£ 5000$, but unlimited under s 77 FOIA since section 85 of the Legal Aid, Sentencing and Punishment of Offenders Act came into force on 12 March 2015.

${ }^{31}$ Freedom of Information (Amendment) (Scotland) Act 2013

${ }^{32} \mathrm{~s} 65$ A FOISA stipulates that prosecutions must be commenced within 6 months of discovery of the commission of an offence provided that the offence was committed no more than 3 years ago.

${ }^{33}$ s127 of the Magistrates' Courts Act 1980 stipulates that any prosecution of for a summary offence must commence within 6 months of the offence being committed, unless legislation specifies otherwise.

${ }^{34}$ Independent Commission on Freedom of Information, Report, (1 March 2016) 16, available at: https://www.gov.uk/government/uploads/system/uploads/attachment_data/file/504139/Independent_Fr eedom_of_Information_Commission_Report.pdf

${ }^{35}$ Cabinet Office (n 28)

${ }^{36}$ This ARTICLE 19 'obligation to publish' principle was updated in 2015 to include a recommendation that information proactively published or released in response to requests should be 'made available in open and machine readable formats when applicable, and without restrictions on its further use and publication,' but compliance with this aspect of the principle is not the focus of this
} 
with this principle, both Acts require public authorities to develop, publish and implement a publication scheme, setting out the classes of information they will publish, the manner in which they will publish them and whether or not they intend to charge for any particular publication. ${ }^{37}$ To assist, the Information Commissioners in both jurisdictions have produced 'model' publication schemes. ${ }^{38}$ UK public bodies are legally required to comply with the model publication scheme whereas Scottish public bodies are encouraged but not compelled to adopt the model scheme - they may develop their own 'bespoke' publication scheme. During the passage of the FOIA, legislators expressed an expectation that the Information Commissioner (ICO) would perform a supervisory role in relation to the adequacy and suitability of each public authority's publication scheme. To this end, the ICO can serve an enforcement notice obligating a public body to introduce a publication scheme in compliance with the model scheme where it has not done so. ${ }^{39}$ In Scotland, the SIC can additionally withhold (for proposed schemes) or withdraw approval in respect of bespoke publication schemes. When FOIA was first enacted the model publication scheme was criticized as placing a vague, unenforceable general duty on public bodies to:

decide for themselves what to publish in publication schemes. Although the information commissioner may appear to have enforcement powers by virtue of the approval provisions, the withholding of approval does not have any sanction. ${ }^{40}$

However, these concerns proved to be misplaced since the ICO expressed satisfaction that public authorities did seek to include appropriate information in their publication schemes and was largely positive regarding the enforcement powers he had in respect of the publication schemes in a post-legislative scrutiny of FOIA ten years after its enactment. ${ }^{41}$ Instead, criticism was levelled at the publication scheme for being 'fairly antiquated, ${ }^{42}$ that is, outmoded due to advances in search engine capabilities in that 'It is probably easier to put a request into a search engine than it is to go through formal documents. ${ }^{33}$ Indeed, publication schemes reflect the technology available at the time of legislative enactment - the UK Government only started releasing information through an online search engine in 2004. ${ }^{44}$ The current ease and low cost

paper, since it dealt with in a separate legislative measure: The Re-use of Public Sector Information Regulations 2015, S.I 2015/1415, established a UK-wide (including Scotland) framework for the re-use of public sector information, enforcement of which is overseen by the ICO.

${ }^{37}$ S 19 of FOIA; s23 FOISA

${ }^{38}$ ICO, Model Publication Scheme, available at: https://ico.org.uk/media/fororganisations/documents/1153/model-publication-scheme.pdf; SIC, The Model Publication Scheme, available at:

http://www.itspublicknowledge.info/ScottishPublicAuthorities/PublicationSchemes/TheModelPublicati onScheme.aspx

${ }^{39}$ FOIA s 52(1); FOISA s 51(1) and s 52

${ }^{40}$ Austin (n6)

${ }^{41}$ House of Commons, Justice Committee, Post Legislative Scrutiny of the Freedom of Information Act 2000, First Report of Session 2012-13, Volume I, HC 96-I, Evidence by the Information Commissioner, 12

${ }^{42}$ Ibid Evidence by Roger Gough, Cabinet Member for Business Strategy and Support at Kent County Council, 12

${ }^{43}$ Ibid Evidence by Professor Trevor McMillan, Pro-Vice Chancellor for Research, Lancaster University and Chair of the 1994 Group Research and Enterprise Policy Group, 12

${ }^{44}$ M Cross, 'Direct to your destination,' The Guardian, (4 March 2004) available at: http://www.theguardian.com/technology/2004/mar/04/internet.egovernment 
of making information available online means that in the longer term, both Acts should be amended to obligate public authorities to publish disclosure logs, a practice that some (but not all) authorities currently engage in: 'they publish lists of all previous requests, and you can click on them and find out what the request was and what information was disclosed; it is, as it were, a back record of things that people have asked us. ${ }^{45}$ Public authorities that already do so report that it helps them manage requests by directing requestors to information that has already been published on their website. ${ }^{46}$ The Independent Commission acknowledged the efficacy of disclosure logs and recommended that the Westminster government legislate to impose a requirement on all public authorities who are subject to the [FOIA] and employ 100 or more full time equivalent employees to publish as soon as the information is provided (where practicable), all requests and responses where information is provided in whole or in part to a requestor. ${ }^{47}$ However, the Government of the day did not indicate any intention to implement this recommendation in its response to the Independent Commission's report. ${ }^{48}$

Thus, both Acts comply to a high degree with this principle, but both Acts should be amended to require publication schemes to be supplemented with disclosure logs to increase transparency and accountability of public authorities, particularly as low Internet publishing costs means that public authorities can now easily produce disclosure logs. Since many public authorities will only do so if legally obligated to, a future measure of political support for FOI rights in both jurisdictions will be the introduction or absence of disclosure logs.

(3) Promotion of Open Government principle

The principle of open government aims to promote a change of culture within government and public bodies so that, over time, they become more transparent. It has two aspects: public education, and, tackling any culture of government secrecy.

\section{(a) Public education}

Both Acts contain a range of promotional measures in compliance with the first aspect of this this principle, for instance, both Commissioners provide educational resources on their websites to inform the public of the existence of access rights and how to exercise those rights. Likewise, the Commissioners in both jurisdictions sponsor regular surveys to track awareness of the legislation. In the most recent UK survey of the general public, $82 \%$ confirmed when prompted, awareness of the Freedom of

\footnotetext{
${ }^{45}$ House of Commons, Justice Committee (n 18) Evidence by Professor Hazell, 14

${ }^{46}$ Independent Commission on Freedom of Information: call for evidence responses, Call for evidence responses from Organisations: D to L, 149; London Borough of Richmond Upon Thames have introduced a disclosure log and early indications suggest that it has resulted in a small decrease in FOI requests received, available at:

https://www.gov.uk/government/uploads/system/uploads/attachment_data/file/491616/Responses_D_-L.pdf

${ }^{47}$ Independent Commission on Freedom of Information, Report (n 32) 17

${ }^{48}$ Cabinet Office (n 28)
} 
Information Act. ${ }^{49}$ Similarly, $73 \%$ of Scottish respondents 'had definitely heard of the FOI Act.' 50

\section{(b) Tackling culture of government secrecy}

Also, in an attempt to address any culture of government secrecy, both Acts require their respective Information Commissioner to promote public authority compliance with codes of practice on good practice in dealing with requests for information ${ }^{51}$ and on good practice in keeping, managing, and destroying records. ${ }^{52}$ The Commissioners are under a duty to promote observance of the non-statutory ${ }^{53}$ codes despite the absence of a legal duty on public authorities to follow or even to have regard to them. ${ }^{54}$ The Commissioners can issue a written 'practice recommendation' specifying the steps which in their opinion ought to be taken to promote conformity with the codes if a public body is not in compliance. ${ }^{55}$ The ICO has primarily used this power to address consistently poor practice regarding slow internal reviews and poor records management. ${ }^{56}$ However, the Acts do not specify the consequences of a failure to comply with a practice recommendation. During the passage of FOIA, legislators acknowledged this, but were satisfied that 'The power of naming and shaming should not be underestimated in regard to public sector bodies keen to keep the confidence of the public they serve. ${ }^{57}$ It seems that this was an overly optimistic prediction, as although these measures have resulted in improvements in response times by the public authorities being monitored by the ICO they do not appear to have led to a general improvement in response times across all sectors; indeed, some public authorities have 'slipped back' once the formal monitoring has ended. ${ }^{58}$

\footnotetext{
${ }^{49}$ ComRes, Annual Track 2014 Individuals (Topline findings) ICO, available at: https://ico.org.uk/media/about-the-ico/documents/1043485/annual-track-september-2014individuals.pdf

${ }^{50}$ SIC, IPSOS MORI Public Awareness Survey Results 2014, available at: http://www.itspublicknowledge.info/home/SICReports/OtherReports/PublicAwarenessResearch2014.as $p x$

${ }^{52}$ s 45 FOIA; s 60 FOISA In Scotland the duty is cast upon the Scottish Ministers. These provisions set out what must be included in the code, and allow for different provision to be made for different public authorities. The former also provides that before issuing or revising any code under this section, the secretary of justice must consult the information commissioner and then must subsequently lay any code or revised code before each house of parliament.

${ }^{53}$ S 45 Code of Practice, para 3; Scottish Code of Practice on the Discharge of Functions by Public Authorities under the FOISA, Introduction, issued pursuant to FOISA s 60.

${ }^{54}$ S 47(1) FOIA; s 43(1) FOISA. The s 45 Code of Practice, para 3 provides that authorities are expected to abide by the Code unless there are good reasons, capable of being justified to the information commissioner, why it would be inappropriate to do so.

${ }^{55}$ S 48(1) FOIA; s 44(1) FOISA The Information Commissioner is required to consult the keeper of the Public Records (or Deputy Keeper in NI) before giving a practice recommendation relating to the Lord Chancellor's code of practice on record-keeping, s 48(3) and 48(4) FOIA

${ }^{56} \mathrm{~J}$ Goodall, \& O Gay, (2010) Freedom of information: the first five years, Standard Note SN/PC/05666, available at: http://www.parliament.uk/briefing-papers/SN05666.pdf

${ }^{57}$ Section 45 Code of Practice on the discharge of the Functions of Public Authorities under Part 1 of the Freedom of Information Act, 2000 Foreword, para 7, which states: 'practice recommendation is simply a recommendation and cannot be directly enforced by the information commissioner. However, a failure to comply with a practice recommendation may lead to a failure to comply with the Act. Further, a failure to take account of a practice recommendation may lead to an adverse comment in a report to Parliament by the Commissioner.'

${ }^{58}$ M Rosenbaum, 'Cabinet Office delays over freedom of information,' BBC News, (4 August 2015), available at: http://www.bbc.co.uk/news/uk-politics-33696753
} 
By contrast, the Scottish Information Commissioner (SIC) has developed a particularly effective practice for monitoring public authority performance with FOISA obligations. Since April 2013, Scottish public authorities have provided the SIC with data about the information requests received, on a quarterly basis via an online statistics portal. ${ }^{59}$ The SIC has confirmed that although public authorities are not legally obliged to submit statistics, the voluntary reporting practice has proved a success, achieving 100\% response rate by authorities. ${ }^{60}$ The SIC uses this information to monitor performance and intervene ${ }^{61}$ where an authority's practice is or may be in breach of its statutory duties or failing to comply with the s 60 code of practice. ${ }^{62}$

In oral evidence to the Independent Commission the ICO expressed enthusiasm for the introduction of a similar scheme in respect of FOIA but pointed out that it would need to be properly resourced. ${ }^{63}$ Indeed, this ARTICLE 19 principle recommends that 'the law should require that adequate resources and attention are devoted to the question of promoting the goals of the legislation.' However, the ICO has experienced a budget cuts (in excess of 30\% since 2011) ) $^{64}$ whilst the SIC has suffered less severe yet significant budget cuts (15\% since 2011$)^{65}$ impacting upon their ability to dedicate resources to promotional and educational activities. The Independent Commission accepted the need for the ICO to have both greater monitoring powers and adequate resources, recommending that the Westminster government legislate to impose a requirement on all public authorities who are subject to the Act and employ 100 or more full time equivalent employees to submit for publication, by either the ICO or a department of the government's choosing, statistics on their compliance under the Act, ${ }^{66}$ and further recommending that the government review whether the funding provided to the ICO is adequate. ${ }^{67}$ However, the Government's response indicated an intention to partially accept the Independent Commission's recommendation in agreeing to issue guidance in the revised section 45 code of practice to set a standard that public authorities with 100 full time equivalent employees or more should publish

\footnotetext{
${ }^{59}$ SIC Statistics portal, available at: https://stats.itspublicknowledge.info

${ }^{60}$ The SIC confirmed $100 \%$ compliance with this voluntary reporting practice in response to an information request made by the author, SIC letter Ref: 201600134, ( $2^{\text {nd }}$ February 2016)

${ }^{61}$ SIC, (2015) Briefings and Guidance, Intervention Procedures, available at: http://www.itspublicknowledge.info/Law/FOISA-EIRsGuidance/Briefings.aspx

${ }^{62}$ SIC, (2014) Scottish Ministers' Code of Practice On The Discharge Of Functions By Scottish Public Authorities Under The Freedom Of Information (Scotland) Act 2002 And The Environmental Information (Scotland) Regulations 2004, SG/2014/245

${ }^{63} \mathrm{C}$ Graham, Independent Commission on Freedom of Information Oral evidence session: 25 January 2015, uncorrected transcript, available at: https://www.gov.uk/government/uploads/system/uploads/attachment_data/file/494934/ICFOI-oralevidence-transcript-25-January16.pdf

${ }^{64}$ House of Commons, Justice Committee - Ninth Report, 'The functions, powers and resources of the Information Commissioner,' Written evidence from the Information Commissioner, (HC 962), para. 4, available at: http://www.publications.parliament.uk/pa/cm201213/cmselect/cmjust/962/962we02.htm; In the financial year 2008-09 the ICO received $£ 5.6$ grant in aid, this was reduced to $£ 3.7 \mathrm{~m}$ in the financial year 2014-15.

${ }^{65}$ SIC, (2014) '2013/14 Annual Report Taking FOI forward.' 28, available at: http://www.itspublicknowledge.info/nmsruntime/saveasdialog.aspx? $l I D=7920 \& s I D=234$; The SIC confirmed that the budget reduction referred to in the 2013/14 annual report was $15 \%$ (in real-terms) in total over the financial years 2011/12,2012/13 and 2013/14 in response to an information request made by the author, SIC letter Ref: 201501311, (23 ${ }^{\text {rd }}$ July 2015)

${ }^{66}$ Independent Commission on Freedom of Information, Report, (n 32) 17

${ }^{67}$ Independent Commission on Freedom of Information, Report (n 32) 50
} 
such information, but it did not indicate an intention to review whether the funding provided to the ICO is adequate. ${ }^{68}$

Overall, both FOIA and FOISA are partially compliant with this principle. To strengthen observance of statutory obligations under FOIA and the s45 non-statutory code of practice, ${ }^{69}$ the Westminster Government indicated an intention to implement the Independent Commission's recommendation to require public authorities with 100 or more employees to submit performance statistics on a quarterly basis, but it did not give effect to this intention. By contrast, FOISA permits small authorities that share administrative functions with another authority (e.g. some licensing boards and non-Ministerial Officeholders) to submit collated statistics. Arguably this approach is better than the de minimis approach under FOIA since it allows the SIC to gain some evidence on the degree of compliance with FOISA by small public authorities without imposing excessively burdensome quarterly reporting obligations, whereas such evidence is less readily available to the ICO. The common weakness in both Acts is the lack of resources available to both Information Commissioners for education and monitoring performance compliance. An acid test of Westminster governmental support for FOI rights in the coming decade will be the provision of adequate resources to support the ICO in the face of austerity cuts. ${ }^{70}$

\section{(4) Limited Scope of Exceptions principle}

An inevitable tension exists between the principle of the right to know and any claim a government makes to restrict disclosure. Extensive exemptions would undermine the efficacy of the right to access information by inhibiting transparency. Accordingly, this ARTICLE 19 principle states that no public authorities should be completely excluded from the ambit of the law, that information requested should be supplied unless it falls within the scope of limited exceptions and that refusal to disclose information should not justified unless it satisfies a strict three-part test: (i) the information relates to a legitimate aim listed in the law; (ii) disclosure would cause substantial harm to that aim; and (ii) the harm to the aim would be greater than the public interest in disclosing the information. This principle also states that information that is withheld should be routinely reviewed to ensure that the exemption still applies, and that exceptions should be limited to no more than 15 years, except in extraordinary circumstances. It is beyond the scope of this article to investigate every exemption listed in both Acts. Instead, it provides a broad comparative overview of the exemptions in both Acts before focusing on the aspects that have proved most controversial, namely, the 'royal family communications,' 'safe space for policy discussions', and relatedly, the ministerial power of veto.

\section{(a) Overview of exemptions}

The exclusion of some intelligence service bodies (M15, M16, GCHQ are excluded, whereas, the National Counter Intelligence Office and the Intelligence and Security

\footnotetext{
${ }^{68}$ Cabinet Office (n 28)

${ }^{69}$ Secretary of State for Constitutional Affairs' Code of Practice on the discharge of public authorities' functions under Part 1 of the Freedom of Information Act 2000, Issued under section 45 of the Act, (2004) HC 33

${ }^{70}$ The same test cannot be used in respect of FOISA since the ICO receives an annual grant-in-aid from the Department for Culture, Media and Sport to fund the costs of her office in undertaking her statutory duties in respect of freedom of information, whereas, the SIC is funded by the Scottish Parliament through the corporate body, and its members are elected as individuals to represent the interests of all the MSPs and not as party representatives.
} 
Committee are included) from FOIA and omission of some but not all defence bodies (the Ministry of Defence is subject to FOIA, and requests can be made of the Army, Royal Navy, Royal Air Force and Royal Marines but not the Special Air Service or the Special Boat Service) from Schedule 1 of FOIA (defence is a reserved matter, so could not be included in FOISA) means it is not fully compliant with this principle's recommendation that 'no public bodies should be completely excluded from the ambit of the law, even if the majority of their functions fall within the zone of exceptions.' Additionally, both Acts contain 'absolute' exemptions that are not subject to any public interest test, and 'qualified' exemptions where the duty to disclose does not apply if, in all the circumstances of the case, the public interest in maintaining the exemption outweighs the public interest in disclosing the information. In compliance with this principle, FOISA contains a 'substantial harm' test whereas FOIA adopted a weaker, 'would, or would be likely to, prejudice' test. In effect, the FOIA test makes it easier for public authorities to refuse information requests, an anomaly not lost on journalists who tactically submit requests under FOISA in respect of information on 'relations between the administrations of the United Kingdom' 71 since they are more likely to succeed than if an identical request were submitted under FOIA. ${ }^{72}$

\section{(b) Royal family communications: absolute v qualified exemption}

An absolute exemption, concerning royal correspondence, was added to FOIA in response to an information request in respect of correspondence between the heir to the throne and government departments which led to $R$ (Evans) v HM Attorney General ${ }^{73}$ an epic, decade-long, legal battle, ${ }^{74}$ that determined disclosure of the correspondence was in the public interest. However, as the case proceeded through the courts, provisions in the Constitutional Reform and Governance Act 2010 to amend s37 of FOIA were commenced to create an absolute exemption in respect of information relating to communications with the 'Sovereign, the Heir to the Throne and the second in line to the Throne, and those acting on their behalf.' The Scottish Government attempted to, but did not succeed, in introducing a similar exemption. It consulted upon, before ultimately rejecting, a similar proposed amendment to FOISA, ${ }^{75}$ on the basis that it had received numerous objections to the proposed amendment, not least from the then SIC who stated: 'Absolute exemptions are not regarded as good practice, and I consider this measure to be unnecessary, ${ }^{, 76}$ with the newly appointed SIC giving oral evidence that under the existing qualified exemption, 'there is already adequate provision for the royal family and for discussions that any public authority may need to have that are confidential, are covered by other rights or are a matter for national security. ${ }^{37}$

\footnotetext{
${ }^{71}$ s 28 of both FOIA 2000 and FOISA 2002

${ }^{72}$ H Brooke, Your Right to Know (2007) 22

${ }^{73}$ [2015] UKSC 21.

${ }^{74}$ For an overview of the case see K Mc Cullagh, 'A tangled web of access to information: reflections on R (on the application of Evans) and another v Her Majesty's Attorney General,' (2015) 21 European Journal of Current Legal Issues 2, available at: http://webjcli.org/article/view/432

${ }^{75}$ Scottish Parliament, Freedom of Information (Scotland) Bill, available at:

http://www.scottish.parliament.uk/S4_Bills/Freedom\%20of\%20Information\%20(Amendment)\%20(Scot land)\%20Bill/b14s4-introd.pdf

${ }^{76}$ Scottish Parliament, 6th Report, 2012 (Session 4): Stage 1 Report on the Freedom of Information (Amendment) (Scotland) Bill, SP Paper 201, available at: http://www.scottish.parliament.uk/S4_FinanceCommittee/Reports/fir-12-06w.pdf

${ }^{77}$ Scottish Parliament Finance Committee, Official Report, Freedom Of Information (Amendment) (Scotland) Bill: Stage 1, 12 September 2012, Col 1515
} 
No evidence was adduced that the public interest test in respect of the existing qualified exemption had been abused, suggesting that an appropriate balance had been struck between FOI and privacy. In response to a suggestion by Deputy First Minister, Nicola Sturgeon, that the amendment should be introduced to ensure consistency of approach across the UK in respect of both the current and the future head of state, the Convenor of the Finance Committee observed that this was not a good reason as,

the Queen is also the head of state of Canada, New Zealand and Australia and I do not believe that they have consistent relations with the UK on this issue. We have a shared monarchy, but we do not necessarily have to have the same rules and regulations. ${ }^{78}$

That such an amendment would generate disparity of access to information in comparison to requests made under the Environmental Information Regulations was cited as further justification for not introducing an absolute exemption in respect of royal correspondence. Such evidence prompted the Finance Committee to pronounce that it remained 'unconvinced of the need for this provision' and call for it to be withdrawn from the Bill, ${ }^{79}$ which it duly was at the second stage. The decision by the Scottish Government to retain a qualified exemption means that FOISA complies with the 'limited scope of exceptions' principle to a greater degree than FOIA.

\section{(c) 'safe space' exemption}

Whilst it is a truism that increasing transparency and accountability through the disclosure of information underpinning government decisions lies at the heart of FOI laws it is also trite that a government could not develop policies or operate effectively if it did not have 'safe space' for discussion, debate and disagreement as enshrined in the constitutional convention of cabinet responsibility, and in International law. ${ }^{80}$ Politicians were naturally concerned that this 'safe space' would be threatened if FOI laws permitted premature or inappropriate disclosure of government information. Accordingly, legislators sought to assuage their concerns by introducing qualified exemptions regarding the formulation of government policy ${ }^{81}$ and the disclosure of material that would prejudice the effective conduct of public affairs ${ }^{82}$ in both jurisdictions. In both jurisdictions requests for information regarding policy have been met with stiff resistance, with both governments making extensive claims that disclosure would substantially inhibit free and frank exchanges inside government.

Indeed, the Independent Commission recommended amending the s35 qualified exemption in a variety of ways such as: amending s35 to clarify that that s35(1)(a) can protect information which would disclose internal communications that

\footnotetext{
${ }^{78}$ Scottish Parliament Finance Committee. Official Report, 12 September 2012, Col 1522,

${ }^{79}$ Scottish Parliament, 6th Report, 2012 (Session 4): Stage 1 Report on the Freedom of Information (Amendment) (Scotland) Bill, SP Paper 201, available at: http://www.scottish.parliament.uk/S4_FinanceCommittee/Reports/fir-12-06w.pdf

${ }^{80}$ The Council of Europe Convention on Access to Official Documents (not yet ratified by the United Kingdom) recognises that the protection of deliberations within or between public authorities concerning the examination of a matter is a legitimate limitation to the right of access to information. The Convention however, states that this is not an absolute exception - it is only applicable when the protected interest may be harmed by its publication, unless there is an overriding public interest in disclosure.

${ }^{81}$ s35 FOIA; s 29 FOISA

${ }^{82}$ s36 FOIA; 30 FOISA
} 
relate to government policy and that $\mathrm{s} 35(1)(\mathrm{b})$ can protect information relating to collective Cabinet decision making. The exemption should also make clear that when considering the public interest, the public interest in maintaining the exemption should not be weakened simply because the relevant policy decision had already been taken. ${ }^{83}$ The Cabinet Office indicated that the Government would 'not make any legal changes to FOI' 84 in response to the Commission's report, which was a welcome development as giving legislative effect to these proposals would steer the public interest test towards refusals to release information, potentially resulting in less information being disclosed under FOIA in future, particularly if uncertainty exists regarding when it is appropriate to disclose information 'after a decision has been taken in the matter.' If information was not disclosed on a timely basis then neither opposition parties, the media, nor the public would know whether a policy decision was made for objectively sound reasons as opposed to short-term political gain, that is, valuable opportunities for scrutiny, debate and refinement of thinking would be lost. It could lead to a return to the pre-FOI era in which all government information is secret until it chooses to disclose it and it will naturally not be minded to disclose it until it has lost its political 'currency.'

\section{(d) Power of Ministerial veto}

Given that this ARTICLE 19 principle recommends narrow, exhaustive limitations, the inclusion of a ministerial power to issue certificates that override decisions in favour of disclosure on public interest grounds in both Acts is problematic. Under FOISA, the first minister can (following consultation with the Scottish Ministers) issue a certificate overriding a decision of the Commissioner where certain exemptions have been applied ${ }^{85}$ in relation to a decision notice served on the Scottish Administration. The First Minister must be satisfied on reasonable grounds that the information is 'of exceptional sensitivity' before a certificate can be applied. ${ }^{86}$ Under FOIA an accountable person, that is, a Minister or the Attorney General can issue a certificate overriding a decision of the Commissioner/Tribunal that disclosure is in the public interest, and a decision notice to that effect has been served on a government department of public authority. The accountable person must have reasonable grounds for issuing the certificate and present it to the Commissioner and lay a copy before each House within 20 working days of the decision, ${ }^{87}$ and the veto power is intended to be used only in exceptional circumstances to pre-empt or overturn appeal rulings. ${ }^{88}$ On a positive note, no First Minister has ever sought to exercise the veto power. At first glance, it appears that it has also been rarely used by Westminster MPs - only seven vetoes in a ten-year period, in comparison to 48 vetoes in the first four years of existence of the Australian FOI law. ${ }^{89}$ However, each ministerial certificate represents an occasion on which the executive has overridden a judicial decision in contravention of the traditional doctrine of separation of powers

\footnotetext{
${ }^{83}$ Independent Commission on Freedom of Information, Report (n 32) 25-29

${ }^{84}$ Cabinet Office (n 28)

${ }^{85}$ ss 29, 31(1), 32(1)(b), 34, 36(1) and 41(b)

${ }^{86} \mathrm{~s} 52(2)$.

${ }^{87}$ It is slightly different under FOISA (30 working days to issue certificate and then 10 working days to lay it before Scottish Parliament and serve copy of reasons on requester - see sections 52(2) and (3) of FOISA)

${ }^{88}$ Legal advice on hostilities in Iraq, Devolution Cabinet minutes, Devolution Cabinet minutes, NHS risk registers, Hostilities against Iraq 2003, Correspondence from Prince Charles and HS2

${ }^{89}$ R Hazell \& B Worthy, 'Assessing the performance of freedom of information,' (2010) 27

Government Information Quarterly 352-359
} 
prompting the Lord Chief Justice in Evans ${ }^{90}$ to describe the veto power as 'a constitutional aberration. ${ }^{91}$ Future use of the veto was uncertain following Lord Neuberger's proclamation that if Parliament intends to permit the executive to override a judicial decision merely because it disagrees with that decision, it must 'squarely confront what it is doing' and make its intentions 'crystal clear, ${ }^{9} 92$ which in the absence of legislative reform, appeared to limit usage of the veto. In response, the Independent Commission made a number of recommendations, which if implemented would lead to stronger but narrower veto powers. These recommendations include: amending FOIA 'to put beyond doubt that it has the power to exercise a veto over the release of information under the Act,' amending FOIA so that the executive veto is available to overturn a decision of the ICO only (removing potential vetoes in respect of Tribunal decisions) where the accountable person takes a different view of the public interest in disclosure, the effect of which would be that where a veto is exercised, appeal rights would fall away and a challenge to the exercise of the veto would be by way of judicial review to the High Court. The Independent Commission further recommended that the Westminster government consider whether the amended veto should make clear that the fact that the government could choose to appeal instead of issuing a veto will not be a relevant factor in determining the lawfulness of an exercise of the veto, and advised that until legislation is enacted, the government should only exercise the veto to overturn a decision of the ICO. Furthermore, the Independent Commission recommended that the Westminster government legislate to allow the veto to also be exercised where the ICO upholds a decision of a public authority (in effect a confirmatory veto agreeing with the ICO's decision), so that the right of appeal would fall away and could only be challenged by way of judicial review. ${ }^{93}$ However, whilst the Government response to the Independent Commission's report 94 indicated that it agreed with the Commission's analysis that 'Parliament intended the executive to be able to have the final say as to whether information should be released under the Act, ${ }^{95}$ the Cabinet minister responsible for FOIA stated that the Government did not intend to legislate to amend the veto powers, preferring instead to modify it's practices in deploying the veto: in future the government will 'only deploy the veto after an Information Commissioner decision, ${ }^{96}$ and further stated that if this approach proves effective it will not bring forward legislation to give effect to the other recommendations by the Independent Commission, but has retained the option of bolstering the veto power in law if necessary. ${ }^{97}$ By contrast, the Scottish Parliament did not review the ministerial veto power when debating whether to reclassify royal correspondence as 'absolute' or signal any intention to do so post-Evans - a sign that the Scottish government has no intention of strengthening the veto power.

The divergent approaches to the veto power are indicative of differing political cultures. The Scottish Government has, since its inception, been broadly supportive of a culture of openness and transparency, and accordingly, has not sought to use the veto power, whereas politicians in the Westminster Parliament that have experienced a long history of secrecy continue to struggle to foster a culture of openness and

\footnotetext{
${ }^{90}$ Evans, $R$ (on the application of) v HM Attorney General \& Anor [2013] EWHC 1960 (Admin)

${ }^{91}$ Ibid para 2

${ }^{92}$ Ibid paras 56-58

${ }^{93}$ Independent Commission on Freedom of Information, Report (n 32$) 40$

${ }^{94}$ Cabinet Office (n 28)

${ }^{95}$ Ibid

${ }^{96}$ Ibid

${ }^{97}$ Ibid
} 
transparency, particularly in relation to information that might cause a minister embarrassment or expose weaknesses and deficiencies in government policies and decisions, hence their insistence on retaining the power to issue vetoes after ICO decisions have been made.

Overall, neither Act is fully compliant with this principle. There is a pressing need to amend FOIA so that it contains a 'substantial harm' test rather than a mere 'prejudice' test, so that it is more difficult for public authorities to refuse information requests. Until then, FOIA will offer weaker information rights. Moreover, the Scottish government has complied with the 'spirit' of this principle in never exercising the veto power, but to ensure full compliance in the future it should amend FOISA to remove it. By contrast, the Westminster Government's stated intention to retain the veto power means that FOIA does not comply with this principle. The Scottish experience has confirmed that it is unnecessary, and it is to be hoped that Westminster politicians will choose to learn from this experience in the future.

(5) Processes to facilitate access principle

This principle contains measures concerning the processing of requests and an independent appeal process in recognition of the fact that a recalcitrant public authority could employ strategies such as making the application process difficult, delaying responding, and either having no appeal process to challenge non-disclosure decisions or having an excessively lengthy and expensive appeal process to avoid fulfilling information requests.

\section{(a) Measures concerning the fulfillment of requests}

Whilst both Acts include a duty to give written reasons for request refusals, ${ }^{98}$ oblige public authorities to assist requestors in refining their requests, ${ }^{99}$ permit public authorities to refer requesters to published material in respect of repeat requests, and refuse vexatious requests, ${ }^{100}$ in compliance with this principle, there are marked differences in respect of the requirement to provide timely responses. FOISA complies with the recommendation that 'the law should provide for strict time limits for the processing of requests on no more than one month'101 in that it obliges Scottish public authorities to respond within 20 working days. ${ }^{102}$ At first glance FOIA appears to impose a similar time limit of 20 days ${ }^{103}$ but if the request pertains to information that

\footnotetext{
${ }^{98}$ s 17(1) FOIA; s 16 (1) FOISA

${ }^{99} \mathrm{~s} 16$ FOIA, s15 FOISA

100 s 14 FOIA; s14 FOISA; The term vexatious is not defined in either Act, but in Dransfield $v$ The Information Commissioner [2015] EWCA Civ 454, the Court of Appeal held that all of the relevant circumstances must be considered, including the motivation behind the request and the history between the requestor and the public authority, and the cost of compliance with the request, provided such considerations are balanced against the benefits of disclosure. The SIC recently issued guidelines along similar lines. SIC (2015) FOISA / EIRS Guidance Vexatious, repeated or manifestly unreasonable requests- A guide to the Scottish Information Commissioner's approach.

${ }^{101}$ The 1999 version of the principles stated that 'requests for information should be processed quickly, and within strict time limits.' The revised wording introduces a stricter time limit, recommending that responses be provided within one month.

${ }^{102}$ s10; 30 if transferred to the Keeper of Records; At section 73 of FOISA 2002 a 'working day' is defined as any day other than a Saturday, Sunday, Christmas Day or a day which otherwise constitutes a bank holiday in Scotland.

${ }^{103} \mathrm{~S}$ 10(6) FOIA stipulates that a bank holiday falling in any part of the United Kingdom counts as a non-working-day for the purposes of FOIA. So, as January 2 nd (or the nearest substitute day) is a bank holiday in Scotland, it is not a working day for the purposes of calculating the maximum timescale for
} 
may be the subject of a qualified exemption then the response time is 'such time as is reasonable in the circumstances' to allow the public authority to consider the public interest balance. ${ }^{104}$ Thus, in many instances, public authorities send a 'holding' response within the 20-day period and take much longer to fulfill the request.

The Independent Commission concluded that the slow response times by public authorities was unacceptable, and recommended that the Westminster government amend section 10(3) of FOIA to limit the period for which public authorities can extend the deadline for a response when considering the public interest to 20 days. Such an extension would only be available when the request involves information that is complex, high volume, or where consultation with a third party is necessary. If given legislative effect, this recommendation would improve the effectiveness of FOIA, ${ }^{105}$ but the Government was silent on this issue in its response to the Independent Commission's recommendations. ${ }^{106}$ Thus, FOISA offers stronger information rights in facilitating timely responses, whereas requests made under FOIA may be delayed by a recalcitrant authority until the information has lost its newsworthiness or political currency; amounting to weaker information access rights that are arguably not fit for purpose. This will not improve until the time frame for responding under FOIA is reduced.

\section{(b) A three-tier appeal processes}

This ARTICLE 19 principle recommends a three tier appeal process comprising an internal review within the public body; appeal to an independent administrative body; and a 'merits' appeal to the courts. The aim is to provide a fast, cost-effective appeal process.

FOISA contains a three-tier appeal process; the first tier comprises a right to ask a public body to conduct an internal review of its decision, which must be conducted and responded to within 20 working days of the request for review. ${ }^{107}$ The second tier permits a requester who remains dissatisfied after the mandatory internal review to ask the SIC to 'make a decision' which should be issued within four months, or a reasonable time period.' ${ }^{108}$ FOISA permits the SIC to attempt to informally effect a settlement before reaching decision, in an effort to provide a speedy, cost-effective solution. ${ }^{109} \mathrm{~A}$ right of appeal to a tribunal was considered but rejected during the legislative drafting process of FOISA on the basis that it would: 'add an unnecessary layer of bureaucracy and possibly undermine the Commissioner's powers', 110 that is, decisions would be more likely to be challenged if information requesters and public authorities knew they could be appealed to a tribunal, and public authorities could use it to delay releasing information that loses 'currency' over time. However, one consequence of the lack of Tribunal appeal stage is that appeals are more expensive in

compliance with a request made under FOIA. For more information, see: J Baines, 'What a difference

a day makes,' (15 ${ }^{\text {th }}$ June 2015), available at: http://informationrightsandwrongs.com

${ }^{104} \mathrm{~s} 10 ; \mathrm{s} 17(2)$ and (3).

${ }^{105}$ Independent Commission on Freedom of Information, Report (n 32) 14

${ }^{106}$ Cabinet Office (n 28)

${ }^{107} \mathrm{~s} 21$; (30 days if information held by Keeper and another authority has to carry out review)

${ }^{108}$ Appeals should be made to the SIC within six months - although the SIC can accept a late appeal where appropriate to do so. s49(4)) If the SIC fails to make a decision within four months, or other reasonable period, then an information requester has the right to seek a judicial review by the Court of Session. The SIC must report annually to Scottish Parliament on the number of decisions which take longer than four months $-\mathrm{s} 46(2)$.

$109 \mathrm{~s} 49(4))$.

${ }^{110}$ CFOI, (2009) 'Freedom of Information in the Devolved Scotland, available at: http://www.centrefoi.org.uk/portal/images/foi_devolved_scotland_speech09.pdf 
Scotland. Also, although FOISA does contain a third level of appeal it may only be made 'on a point of law' against a decision by the SIC to the Inner House of the Court of Session, instead of a full 'merits' review by a court, as this principle recommends. ${ }^{111}$

FOIA is not fully compliant with this principle either because it an excessive number of tiers of appeal. Unlike FOISA, it does not require internal review by a public authority, though in compliance with the code of practice, many public authorities do have an internal review procedure. Where one exists, it must be used before a requester can appeal to the ICO for a decision. ${ }^{112}$ However, a comparative weakness is that no time period for completion of internal reviews exists ${ }^{113}$ so requesters often experience frustrating delays. ${ }^{114}$ To address this, the Independent Commission has recommended that the government amend FOIA to impose a statutory time limit for internal reviews of 20 working days, which would bring it in line with the FOISA time limits. ${ }^{115}$

At present, where no internal review exists or it has been exhausted, those refused access to information can complain to the ICO to make a determination. ${ }^{116}$ Unlike FOISA, no provision exists under FOIA for the ICO to effect a settlement though complaints are routinely resolved informally by the ICO. Problematically, a backlog of complaints causes delay in ICO determinations (e.g. up to 23 months). An appeal, on merits as well as points of law, lies to the First-Tier (FTT) tribunal, then the Upper Tier Tribunal (UTT) can hear appeals from the FTT on a point of law if permission is granted by either the FTT, or if refused by the FTT, the UTT itself. Particularly complex and/or important matters may be transferred to the UTT (Administrative Appeals Chamber) under the Tribunal Rules, whilst an appeal on a point of law only, lies to the High Court, the Court of Appeal and, where necessary, to the Supreme Court. However, legal aid is not available for judicial proceedings, which has the potential to deter applicants. Indeed, FOIA has been criticized for employing 'the most elaborate appeals processes of any in the world' ${ }^{117}$ which is complex, time-consuming and expensive to complete - it took ten years from an initial FOI request refusal to an eventual decision by the Supreme Court at a cost in excess of $£ 270,000 .{ }^{118}$ Moreover, if cases are referred back to the First-tier tribunal to be redecided, the process can be even longer. Thus, some cases take years to resolve, by which time the value of the requested information may have diminished, as was arguably the case in respect of letters written by the Prince of Wales to government ministers, which received a muted public reaction, perhaps due to the fact that many of the ministers he had written to were no longer in office, and the political issues were no longer live.

\footnotetext{
${ }^{111}$ A further right of appeal to the Supreme Court in London exists (s 29(2), Scotland Act 1998) for matters outwith the legislative competence of the Scottish Parliament, such as cases concerned with human rights issues under the ECHR. The Supreme Court serves as the final court of appeal in such matters; to date just one FOISA case has been considered: South Lanarkshire Council v The Scottish Information Commissioner [2013] UKSC 55

112 s 51 FOIA; s50 FOISA

${ }^{113}$ The ICO recommends that they are completed within 20 days

${ }^{114}$ House of Commons Justice Committee (n 18) 39-40

${ }^{115}$ Independent Commission on Freedom of Information, Report (n 32) 15

${ }^{116} \mathrm{~S} 50$ (2) states that Commissioner can refuse to come to a decision if the applicant has not exhausted all remedies. Commissioner can refuse to investigate a case where there has been undue delay in appealing to him.

${ }^{117}$ CFOI, (2009). 'Press Release: Iraq veto decision "extremely retrograde,"' available at: http://www.cfoi.org.uk/foi240209pr.html

${ }^{118} R$ (Evans) v HM Attorney General [2015] UKSC 21
} 
The Independent Commission acknowledged that FOIA contains an excessive number of layers of appeal and recommended that the Westminster government legislate to remove the right of appeal to the First-Tier Tribunal against decisions of the ICO on the basis that First-Tier Tribunal appeals too closely duplicate the full merits assessment conducted by the ICO. Removing this level of appeal would arguably strengthen the position of the ICO as the final arbiter of the substance of cases whilst also speeding up the appeal process and reducing the overall costs involved in pursuing an appeal. Appeals would still lie to the Upper Tribunal, only on a point of law. ${ }^{119}$ However, the Government's response to the Independent Commission's report was silent on the issue of reducing the tiers of appeal. ${ }^{120}$ It cannot be achieved without legislative reform, so FOIA will continue to have an excessive number of tiers of appeal for the foreseeable future.

Overall, neither Act is fully compliant with this principle. To achieve full compliance, FOISA should be revised to include a Tribunal tier of appeal so that costs are reduced for those challenging non-disclosure decisions, and it should be revised to permit a full merits review by the Inner House of the Court of Session.

Likewise, the appeal process under FOIA should be amended to ensure that it is less complex and time consuming e.g. a requirement for public authorities to respond within 20 working days, mandatory internal review by a public authority within 20 days, and the ICO to complete its reviews within a specified time period e.g. within four months, or a reasonable time period, as is the case under FOISA; of course this would have budgetary implications for the ICO and necessitate the provision of additional funding to the ICO's office by the Westminster Government. Furthermore, the Westminster government should give legislative effect to the Independent Commission's recommendation to remove the right of appeal to the First-Tier Tribunal, as so doing, would ensure FOIA is fit for purpose as it enters its second decade.

(6) Reasonable costs principle

In recognition of the financial and personnel burden of responding to requests this principle states that 'the cost of gaining access to information held by public bodies should not prevent people from demanding information of public interest' and that information should be provided 'at no or low cost and limited to the actual cost of reproduction and delivery.'

FOIA permits a public authority to charge for: determining whether the information is held (or not), locating the information, retrieving it, and extracting it when calculating the cost of a request. ${ }^{121}$ If an excessive amount of time would be required to determine whether the information is held or not then there is no statutory requirement to provide it. If the projected cost is within the appropriate limit $(£ 600$ for central government requests and $£ 450$ for all other UK public authorities charged at a flat rate of $£ 25$ per hour) then no fee is charged. These cost limits have remained unchanged since 2005, when they were calculated by reference to the limit set by the Treasury for refusing to answer a parliamentary question on the basis of disproportionate cost (at eight times the average direct cost of civil servants' time

\footnotetext{
${ }^{119}$ Independent Commission on Freedom of Information, Report (n 32) 43

${ }^{120}$ Cabinet Office (n 28)

${ }^{121}$ The Freedom of Information and Data Protection (Appropriate Limit and Fees) Regulations 2004

(SI 2004/3244) (UK Fees Regulations) are used to calculate fees under the FOIA; Reg 4(3)
} 
answering written parliamentary questions). ${ }^{122}$

By contrast, FOISA ${ }^{123}$ permits a public body to charge for the direct and indirect costs incurred in 'locating, retrieving and providing information.' ${ }^{24}$ However, a public body is not entitled to charge for any costs incurred in determining: whether it holds information, ${ }^{125}$ or whether or not the information should be disclosed. Where the projected costs do not exceed $£ 100$ then no fee is payable. Where the projected costs are beyond $£ 100$ but less than $£ 600$ then the fee, if sought from the applicant, should not exceed 10 percent of the difference between the projected costs and the $£ 100$ (free element). Thus, the maximum charge for a potential applicant is $£ 50 .{ }^{126}$ Moreover, the hourly rate for staff locating, retrieving or providing information in Scotland is lower - capped at a maximum of $£ 15$ per hour compared to a flat rate $£ 25$ per hour in the UK. Accordingly, an applicant in Scotland is entitled to 40 hours per request compared to 24 hours per request submitted to a central government department or 18 hours per request submitted to another public body in the UK. The method of calculating costs is, therefore, more 'applicant friendly' in Scotland for two reasons: firstly the lower hourly rate and secondly the approach taken by the SIC to fee calculation. For instance, in Decision 211/2012 127 the SIC determined that rather than simply refusing a request on the basis that the cost would exceed $\mathcal{E}_{6} 600$, the public body should have liaised with the applicant to refine the request so that the bulk of the information requested could be provided. ${ }^{128}$ Subsequently, in Decision $055 / 2013$ the SIC was not satisfied that a fee of $£ 15$ per hour should be charged, finding that the request could be processed by a staff member on a lower pay grade ( $\$ 9.50$ per hour). ${ }^{129}$ In challenging potentially inflated costs, the SIC has encouraged public bodies to adopt a pragmatic approach to the levying of fees for information requests. The ICO should heed this experience, since 'A common complaint about the lowest transparency [Whitehall] departments is that they often lie to inflate these costs so they can refuse releases.' ${ }^{30} \mathrm{~A}$ more robust approach to costs would assist in ensuring greater efficacy.

Both Acts also contain provisions regarding 'aggregate' requests but employ different tests for aggregation. FOIA states that a public authority can aggregate the cost of complying with two or more requests. ${ }^{131}$ A 'thematic' test of 'similarity, to any

\footnotetext{
${ }^{122}$ Hansard, House of Commons debate: Freedom of Information, The Parliamentary Under-Secretary of State for Constitutional Affairs (Mr. Christopher Leslie), $9^{\text {th }}$ June 2004, Col 97WH 
extent' is employed. Thus, in UK Decision FS50503796, an applicant's requests for information from the Metropolitan Police Service regarding the number of surveillance operations undertaken, details relating to staff commitment and the number of persons under surveillance were held to be thematically linked even though not held as an aggregate record. Evidently, thematic aggregation limits the volume of information an applicant can obtain through requests and undermines the effectiveness of the FOIA by acting as a costs deterrent to applicants. By contrast, the aggregation test in FOISA is whether separating the information to assess and calculate the interconnectedness would be 'a wholly artificial exercise'. Thus, multiple requests contained in the same piece of correspondence from the same applicant are read as self-standing submissions, as opposed to constituent parts of the same request. For instance, in Scottish Decision 055/2013 the applicant submitted ten separate letters containing 35 separate information requests to Scottish Ministers requesting information regarding the awarding of a knighthood. The SIC ruled that each request constituted a different request for the purposes of FOISA and, as such, each of the 35 requests assumed its own cost limit. ${ }^{132}$ If the request had been submitted to a UK body that used the 'thematic' test of aggregation then it is likely the applicant would have been costs barred from receiving the information requested. However, under FOISA, if multiple requests are so interconnected that they should be treated as one for the purpose of responding then the request for information may be costs barred. For instance in Scottish Decision 134/2012, the Commissioner was satisfied that the applicant's six requests, for minutes of meetings held by the Scottish Criminal Cases Review Commission could be considered as one because: identification and location of what is required to address each point cannot realistically be separated out into discrete tasks. ${ }^{133}$ It would have been both illogical and impractical for a public body to separate out the request into six different tasks to be dealt with separately. Clearly the Scottish test is pragmatically applicant friendly. It strikes a better balance between facilitating related requests for information and protecting a public body from unrefined 'fishing expeditions' for information than the test used by FOIA.

Overall, the costs calculation measures in FOISA comply with the ARTICLE 19 recommendation to a greater extent than FOIA. The Westminster Government and ICO should learn from the FOISA experience, otherwise recalcitrant public authorities and government departments will continue use fees to both deter and avoid fulfilling information request thereby weakening information access rights and continuing in non-compliance with this ARTICLE 19 principle.

\section{(7) Imperfect compliance}

Evidently, a decade after their implementation, neither Act fully complies with the UN endorsed principles synthetized by the NGO ARTICLE 19. FOISA offers stronger information access rights than FOIA, in terms of s5 power to designate public bodies (supported by the s7A requirement for Scottish Ministers to report to the Scottish Parliament every two years on the use/non-use of s5 powers during the reporting period), costs, fewer exemptions and lack of exercise of the power of ministerial veto, shorter, stricter time-frames for public authorities to respond, and fewer, faster appeal tiers. However, there is a need to review and remove the power of veto from both Acts, reduce the number of tiers of appeal in FOIA, and ensure adequate funding for Commissioners in both jurisdictions to ensure full compliance with the normative principles. The foregoing discussion confirmed that although both

\footnotetext{
${ }^{132}$ Scottish Decision 055/2013, Mr Rami Okasha and the Scottish Ministers.

${ }^{133}$ Scottish Decision 134/2012, Mr S and the Scottish Criminal Cases Review Commission, para 14.
} 
Acts entered into force on the same day and contain many identical provisions, divergences in scope and practices have emerged in the two jurisdictions. This begs the question, why? Are these differences attributable to the political culture of the respective Parliaments?

\section{G. Influence of political cultures?}

Three case studies are examined to determine the impact, if any, of the differing political cultures on information access rights in each jurisdiction.

\section{(a) Attitudes regarding the merits of information rights laws}

FOISA has, since its implementation, received broad continuous political support from some senior MSPs. For instance, a year after FOISA came into effect, Jim Wallace, who introduced the FOI Bill to the Scottish Parliament while Deputy First Minister, recalled fondly a personal political commitment to introduce freedom of information legislation: 'When I first stood for the Westminster Parliament... I committed myself to an FOI Bill' ${ }^{134}$ He had reasoned that 'it wasn't just a change of legislation, which was needed; it was a change of culture'. ${ }^{135} \mathrm{He}$ expressed satisfaction that his election promise had become law and was broadly positive about its impact. A decade after its implementation he remained positive, noting that it had prompted a culture change of greater openness and transparency:

The success of the legislation is not so much that individuals can demand information from public authorities, but that there are an increasing number of occasions when no demand is necessary - the material is readily available. ${ }^{136}$

His disappointment that more had not been done to ensure that it kept pace with changes in public services was remedied later that year when the Scottish Parliament took steps to amend FOISA designation powers.

The positive support for information rights expressed and repeatedly reaffirmed by Scottish politicians is in sharp contrast to the reactions of their Westminster counterparts. Indeed, an ever-present challenge to FOIA's success is that posed by some Westminster politicians, who a decade on, still struggle to accept that freedom of information is a necessary part of the political and legal landscape. For instance, Tony Blair, whose Labour Government introduced FOIA famously decried his decision in his memoirs, stating: 'Freedom of Information ...You naive, foolish, irresponsible nincompoop...so utterly undermining of sensible government?' 137 When he was Prime Minister, Mr David Cameron also displayed naked hostility towards FOIA, stating: 'I wish we'd spent more time in opposition thinking about how to declutter government. What I call the buggeration factor, of consulting... and FOI[A].' ${ }^{138}$

\footnotetext{
${ }^{134}$ J Wallace, (2006) Speech on Freedom of Information, Fourth Freedom of Information Conference at Holyrood, in G John, Relations that Unite and Divide: A Study of Freedom of Information Legislation and Transparency in Scotland, (Unpublished PhD Thesis, University of St Andrews) (2009) 64 135 (n132) 65

${ }^{136}$ Office of the Advocate General for Scotland and The Rt. Hon Lord Wallace of Tankerness QC (2014), 'A speech to mark the tenth anniversary of the Freedom of Information (Scotland) Act's implementation on $1^{\text {st }}$ January 2005 available at: https:/www.gov.uk/government/speeches/ten-yearsof-foisa

${ }^{137}$ T Blair, A Journey (2010) 516

${ }^{138}$ J Russell, '24 hours with David Cameron,' The Times, (28 March 2015)
} 
These are not empty statements, as Roberts has observed that 'the governing institutions in Westminster systems are particularly resilient, and capable of rejecting alien transplantations such as FOI laws, or of developing new routines designed to minimize the disruptive effect of these new laws.' ${ }^{39}$ Indeed, evidence exists which confirms that government departments have adapted their systems and processes to circumvent rather than facilitate information rights. For instance, the then Education Minister ${ }^{140}$ deliberately used a personal email account instead of his official government email account to try to avoid capture by FOIA ${ }^{141}$ prompting the ICO to rebuke the Minister and issue guidance on good practice. ${ }^{142}$ Moreover, the recent transfer of responsibility for FOIA to the Cabinet Office ${ }^{143}$ has raised concerns since this department is so notorious for its poor FOI performance and disclosure evading techniques that it has twice been subject to monitoring by the ICO, ${ }^{144}$ and is the subject of a website entitled: 'Has The ICO Issued An Enforcement Notice Against the Cabinet Office Yet?.'145 Evidently, many Westminster politicians pay lip service to FOIA but remain implacably opposed to it. It remains to be seen whether Theresa May's Conservative Government will introduce a new more open culture.

\section{(b) Behaviour of politicians regarding FOI requests in respect of expenses}

Secondly, a FOISA request in respect of MSP expenses led to the revelation that the Scottish Conservative leader's travel expenses were far in excess of any other MSP, and further that the spending was not all for essential parliamentary travel. The MSP resigned as leader of the Conservative group in Parliament, and the Scottish Parliament promoted openness and transparency through the creation of a searchable on-line database to fulfil future information requests regarding expense claims. ${ }^{146}$ As the then SIC observed

rather than resist further disclosure, the presiding Officer of the Scottish Parliament agreed to the extensive publication of all expense claims, which occasioned no further scandal. ${ }^{147}$

A sharp contrast can be drawn between this and the response to a similar requests submitted in respect of Westminster politicians. The then Speaker of the House

\footnotetext{
${ }^{139}$ A Roberts, Blacked Out: Government Secrecy in the Information Age (2006) 108

${ }^{140}$ (now Justice Minister)

${ }^{141}$ C Cook, 'Labour calls for Gove emails probe,' Financial Times, (20 ${ }^{\text {th }}$ September 2011$)$

${ }^{142}$ ICO, (2011) 'Official information held in private email accounts,' available at:

https://ico.org.uk/media/for-

organisations/documents/1147/official_information_held_in_private_email_accounts.pdf; Retired civil servants confirmed that politically sensitive information is deliberately written on disposable post-it notes in some government departments to frustrate the operation of the act, B Wheeler, 'Post-It notes and the end of written history,' BBC News, $\left(1^{\text {st }}\right.$ July 2015$)$ available at:

http://www.bbc.co.uk/news/10338038

${ }^{143}$ Cabinet Office 'Written statement to Parliament - Freedom of information: new Commission,' (17 July 2015), available at: https://www.gov.uk/government/speeches/freedom-of-information-newcommission

${ }^{144}$ M Rosenbaum, 'Cabinet Office delays over freedom of information,' BBC News, (4 ${ }^{\text {th }}$ August 2015) available at: http://www.bbc.co.uk/news/uk-politics-33696753

${ }^{145}$ Available at: http://hastheicoissuedanenforcementnoticeagainstthecabinetofficeyet.com

${ }^{146}$ R Evans, 'Fare disclosure: The Freedom of Information Act forced the downfall of Scottish Tory leader David McLetchie over his use of taxis, but what else has it revealed to the media in the past year? The Guardian, (2 Jan 2006) available at: http://www.guardian.co.uk/media/2006/jan/02/mondaymediasection.politicsandthemedia

${ }^{147}$ K Dunion, Freedom of Information In Scotland In Practice (2011) 440
} 
appealed against these FOI requests to the ICO, ${ }^{148}$ the Information Tribunal ${ }^{149}$ and, eventually, the High Court. ${ }^{150}$ In the meantime, some MPs tried to amend FOIA through the introduction of a Private Members Bill, which passed through all legislative stages in the Commons, but failed when a sponsor could not be found in the Lords to take it through the upper house. ${ }^{151}$ The protracted (unsuccessful) legal battle and attempt to amend FOIA illustrate the intransigent attitude of some Westminster politicians whose refusal to capitulate in respect of FOI requests was encapsulated in the comment by an MP: 'it's a brave general who surrenders.' 152

\section{(c) Government responses to post-legislative reviews.}

If further evidence were needed of on-going political hostility towards FOIA, one need look no further than the differing response of the two Governments to reports calling for reform. For instance, the first SIC laid before the Scottish Parliament a special report in which he raised concerns that inertia regarding the exercise of designation powers would lead to FOISA becoming out-dated and ineffective. The Scottish Government resisted extending designation for a long time (9 years). It initially claimed it would be premature to designate before remedying deficiencies in the legislation. However, when it became apparent that the deficiencies were largely technical and unrelated to designation, it amended FOISA ${ }^{153}$ to oblige Ministers to report to Parliament on their use of the designation power every two years and give reasons for not using the power if it hasn't done so in the two-year reporting period, 154 and in so doing, reaffirmed its commitment to having effective information access rights laws that are fit for purpose.

By contrast, two reviews of FOIA have been conducted in the last four years. The first post-legislative review was conducted in 2012. The Justice Committee concluded that 'The Freedom of Information Act has been a significant enhancement of our democracy, ${ }^{155}$ and suggested a number of reforms to strengthen its operational effectiveness, including: a 20 day time limit (in the absence of exceptional circumstances) for public authorities to conduct internal reviews, ${ }^{156}$ the publication of data on the timeliness of their responses so that the ICO could monitor organisations with low rates of compliance, ${ }^{157}$ and, making s77 a hybrid offence so that potential prosecutions would not be time-barred. ${ }^{158}$ The Government did not legislate to give effect to these recommendations. A mere three years later, $\mathrm{Mr}$ Cameron's Government established the Independent Commission to review FOIA whose remit included: extending safe space for policy development and strengthening the power of ministerial veto, despite the earlier review finding no clear evidence of problems with

\footnotetext{
${ }^{148}$ ICO 2007 FS50070469: 10;

${ }^{149}$ Information Tribunal EA/0006/0015 and 0016: 5-7; Information Tribunal EA/2007/0060

${ }^{150}$ [2008] EWHC 1084

${ }^{151}$ A Kelso, 'Parliament on its Knees: MPs' Expenses and the Crisis of Transparency at Westminster,' (2009) 80 Pol. Q 3, 329-338.

${ }^{152}$ B Worthy \& G Bourke (2011) 'The Sword and the Shield: The use of FOI by Parliamentarians and the Impact of FOI on Parliament,' 17, available at: https://www.ucl.ac.uk/constitutionunit/research/foi/foi-and-parliament/sword-and-the-shield.pdf

153 The Freedom of Information (Scotland) Act 2002 (Designation of Persons as Scottish Public Authorities) Order 2013.

${ }^{154}$ SIC, (2013) Freedom of Information (Amendment) (Scotland) Act 2013: Briefing Note, available at: http://www.itspublicknowledge.info/nmsruntime/saveasdialog.aspx? $l I D=6932 \& s I D=377$

${ }^{155}$ House of Commons Justice Committee, (n 18) 3

${ }^{156}$ Paras 103, 111, 112

${ }^{157}$ Para 109

${ }^{158}$ Para 121
} 
either. ${ }^{159}$ The Independent Commission's recommendations mirror those called for in the earlier review, but for a second time the Government indicated that it did not intend to give legislative effect to these reform proposals. The political inertia regarding legislative reforms belies claims by the Westminster Government to value FOIA. A strong argument can be made given the remit and phrasing of questions in the most recent review that the true intention of the Westminster Government was to obtain evidence to justify restricting information access rights as opposed to seeking evidence on ways to strengthen it, but they underestimated the ability of civil society, the media and the public to quickly mobilise a strong campaign in support of FOIA. The Independent Commission's consultation received in excess of 30,000 responses, including responses by 140 media groups ${ }^{160}$ and a petition with in excess of 170,000 signatories ${ }^{161}$ calling on the Government to protect FOIA. Also, Senior Conservative politician, David Davis, MP, announced at an all-parliamentary briefing organised by the cross-party campaign to defend freedom of information that enough Tory rebels could be found to oppose any changes to the FOI Act, 'Whatever they come up with, we can find an appropriate response in one house or another.' 162 The refusal to legislate to strengthen FOIA confirms that the Westminster Government led by $\mathrm{Mr}$ Cameron was not minded to support and value FOIA, rather it opted to quietly back away from trying to restrict FOIA in the face of potentially overwhelming opposition, but retained the option to revisit issues such as exercise of the ministerial veto in future. Given the pressing issues flowing from the Brexit vote, it is unlikely to be a legislative priority for Mrs May's Government.

\section{Conclusion}

Clearly, neither Act is currently fully compliant with the ARTICLE 19 principles of good practice. Changes are needed as the FOI laws enter their second decade to strengthen and consolidate the provisions in both Acts so that they are fully compliant with the UN endorsed principles. Implementation of the recommendations in this paper would ensure that. However, it would be foolish to wait with bated breath for the Westminster Government to announce amendments to strengthen FOIA as despite the recent statement by the then Leader of the House of Commons, Chris Grayling, that FOIA is a legitimate and important tool for those who want to understand why and how governments make decisions, and this government does not intend to change that, ${ }^{\prime 63}$ a culture of secrecy is evidently 'alive and kicking' in Westminster, and dealing with the implications of the Breixt referendum (rather than FOI), is likely to be Theresa May's priority. The Scottish Government has also faced challenges in adopting a more open culture. For instance, it was slow to designate new public authorities, and it continues to struggle with requests for information regarding

\footnotetext{
${ }^{159}$ Cabinet Office, Lord Bridge of Headley, Freedom of information: new Commission, (17 July 2015), available at: https://www.gov.uk/government/speeches/freedom-of-information-new-commission

${ }^{160}$ Independent Commission on Freedom of Information: call for evidence responses, available at:

https://www.gov.uk/government/publications/independent-commission-on-freedom-of-information-callfor-evidence-responses

${ }^{161}$ R Falcon, 'Freedom of Information: petition handed in,' (19 Nov 2015), available at: https://home.38degrees.org.uk/2015/11/19/freedom-of-information-petition-handed-in/; In excess of 20,000 signatures were added after the petition was submitted to the Independent Commission.

${ }_{162}$ J Jackson, 'Tory MPs will oppose watering down Freedom of Information Act,' The Guardian, (30 Nov 2015), available at: http://www.theguardian.com/politics/2015/nov/30/tory-mps-will-opposewatering-down-freedom-of-information-act

${ }^{163}$ Hansard, House of Commons debates, 29 October 2015, col. 522.
} 
policy. Nevertheless, it has forged its own path in respect of Freedom Information not feeling obligated to follow the Westminster attitudes, practices or any need to ensure legislative conformity. As a result, stronger information rights have emerged under FOISA than FOIA. The Deputy First Minister's assertion that 'Scotland has most robust Freedom of Information regime in the UK,' was true, but it was the wrong benchmark to choose. A true test of commitment to FOI rights will be passed if the Scottish Government amends FOISA to ensure compliance with the UN endorsed principles. 